\title{
ERRATUM: Junkyard PCR
}

Michael Eisenstein

Nat. Methods 3, 8-9 (2006).

In the version of this article originally published, it was indicated that two groups, Braun \& Libchaber (Phys. Rev. Lett. 89, 188103; 2002) and Krishnan et al. (Science 298, 793; 2002) independently developed the method of convective PCR in 2002. Although Braun \& Libchaber discuss the theoretical potential for convective DNA amplification in their 2002 paper, the article by Krishnan et al. actually describes an

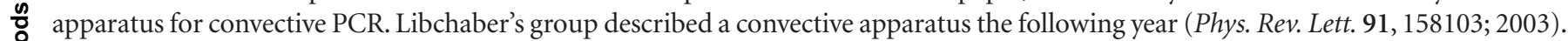

